\title{
Awareness and impact of the 'Bubblewrap' advertising campaign among Aboriginal smokers in Western Australia
}

\author{
Terry Boyle, ${ }^{1}$ Carrington CJ Shepherd, ${ }^{1,2}$ Glenn Pearson, ${ }^{1}$ Heather Monteiro, ${ }^{1}$ \\ Daniel McAullay, ${ }^{1}$ Kristina Economo, ${ }^{3}$ Susan Stewart ${ }^{3}$
}

${ }^{1}$ Kulunga Research Network, Telethon Institute for Child Health Research, Centre for Child Health Research, The University of Western Australia, Perth, Australia ${ }^{2}$ Curtin Health Innovation Research Institute, Centre for Developmental Health, Telethon Institute for Child Health Research, Curtin University of Technology, Perth, Australia ${ }^{3}$ Tobacco Programs, Cancer Council Western Australia, Perth, Australia

\section{Correspondence to} Terry Boyle, Western Australian Institute for Medical Research, B Block, Hospital Avenue, Sir Charles Gairdner Hospital, Nedlands, Western Australia 6009, Australia;

tboyle@waimr.uwa.edu.au

Received 27 May 2009 Accepted 20 October 2009

Published Online First

3 December 2009

\section{ABSTRACT}

Background Antismoking mass media campaigns have been shown to reduce smoking prevalence in the mainstream community, however there is little published research on their effect on Aboriginal Australian smokers.

Objectives To evaluate the awareness and impact of a mainstream mass media advertising campaign (the 'Bubblewrap' campaign) on Aboriginal smokers in the state of Western Australia.

Methods A personal intercept survey was conducted in July 2008 across three sites (the Perth metropolitan area and the non-metropolitan towns of Kalgoorlie and Broome). An opportunity or convenience sampling strategy was used to recruit Aboriginal participants, and face-to-face interviews were conducted with 198 Aboriginal smokers to ascertain awareness of the campaign advertisements, whether they were seen as believable and relevant, and the impact the advertisements had on smoking behaviour.

Results The majority of the participants interviewed had seen and/or heard the 'Bubblewrap' campaign advertisements, although there was considerably greater awareness of the television advertisement than the radio advertisements. Both forms of advertising were considered to be believable and relevant by the majority of Aboriginal smokers. Most of the smokers interviewed thought about cutting down and/or quitting after seeing or hearing the advertisements.

Conclusions Our findings suggest that mainstream antismoking mass media campaigns can positively influence the thoughts and behaviours that Aboriginal smokers have, and exhibit, towards quitting smoking. Notwithstanding this, advertisers should continue to look for better ways to incorporate Aboriginal themes in campaign messages. Future mainstream antismoking campaigns should source sufficient funds to ensure that advertising messages reach the large Aboriginal populations in regional and remote Australia.

\section{INTRODUCTION}

In Australia, Aboriginal adults are more than twice as likely as non-Aboriginal adults to be current daily smokers, ${ }^{1}$ with more than half of all Aboriginal adults being regular smokers. ${ }^{2}$ Tobacco smoking is one of the leading causes of morbidity and mortality among the Aboriginal population: it was responsible for $12 \%$ of the total burden of disease and $20 \%$ of deaths in 2003. ${ }^{3}$ While the smoking prevalence among non-Aboriginal adults has decreased over the last 10 years, the smoking prevalence among Aboriginal adults has remained constant. ${ }^{2}$

At least part of the decrease in smoking prevalence among non-Aboriginal adults in Australia can be attributed to antismoking mass media campaigns. ${ }^{4} 5$ The two published studies that have evaluated the effect of these campaigns among Aboriginal people in Australia have found that they could recall mainstream mass media antismoking campaigns, ${ }^{67}$ however the impact of these campaigns remains unclear.

This study aimed to evaluate the awareness and impact of a mainstream mass media advertising campaign (the 'Bubblewrap' campaign) on Aboriginal smokers in Western Australia.

\section{METHODS}

\section{Advertising campaign}

The Cancer Council Western Australia's 'Make Smoking History' campaign aired 'Bubblewrap' across the state of Western Australia in mid-2008. The 'Bubblewrap' concept was originally developed by Quit Victoria and had been run in Western Australia twice prior, both times in 2005. This campaign used the original 'Bubblewrap' television and radio advertisements in conjunction with a newly produced radio advertisement that specifically targeted adult Aboriginal smokers.

The 30-second television advertisement depicted a piece of plastic bubblewrap in the shape of lungs and showed a hand burning the bubbles one by one with a lit cigarette. The accompanying voiceover explains that lungs are made up of millions of tiny air sacs which are destroyed by chemicals found in tobacco smoke, and that this process is called emphysema. The television advertisement was broadcast on metropolitan, non-metropolitan and Indigenous stations in Western Australia. The original and new 60-second radio advertisements encouraged listeners to undertake a breathing exercise until they felt short of breath, to simulate the symptoms of emphysema. The new radio advertisement was narrated by popular fictional character, 'Mary G', portrayed by Western Australian Aboriginal identity Mark Bin Bakar. The original radio advertisement was aired on metropolitan and regional stations, while the new version was restricted to the audiences of regional and Indigenous stations. All advertisements can be viewed/ heard at http://www.cancerwa.asn.au/prevention/ tobacco/makesmokinghistory/tvcampaigns/ (under the 'Bubblewrap' heading). 
Both forms of advertising were broadcast over 7 week campaign periods in May-June 2008; the television advertisement aired for 6 of 7 weeks from 11 May, while the radio advertisements were played for 4 weeks from 18 May. Measures of television advertising exposure suggest that the majority of the target audience (25-54 year olds) saw the television advertisement during the campaign period. Overall, an estimated $95.2 \%$ of the target audience was exposed to the advertisement at least once, and $86.1 \%$ was exposed three or more times. On average, people in the target audience saw the television advertisement 18 times over the campaign period.

The Target Audience Ratings Points (TARPs) measure is another way of gauging the reach of television advertising. TARPs were generally above 300 per week over the course of the campaign, in metropolitan and non-metropolitan areas of Western Australia. In total, the television advertisement received a total of 1848 TARPs in the Perth metropolitan area and 1473 in non-metropolitan parts of Western Australia.

\section{Evaluation}

The evaluation of the campaign was carried out in July 2008, and took place across three sites (the Perth metropolitan area and the non-metropolitan towns of Kalgoorlie and Broome) to provide a broadly representative mix of metropolitan and nonmetropolitan participants. The study was conducted as a personal intercept survey, with face-to-face interviews held with Aboriginal smokers in various locations (medical and community centres, public spaces and main pedestrian thoroughfares, and at public events) within each of the three study sites. The locations were chosen in order to maximise exposure to the target group and enable access to a broad cross-section of Aboriginal people.

The study used an opportunity or convenience sampling strategy. Potential participants were approached consecutively in $2-3 \mathrm{~h}$ time periods, in normal business hours. Staff and clients were approached in medical and community centre settings, where access had been provided by prior agreement. To be eligible for the study, participants had to identify as being Aboriginal and/or Torres Strait Islander, and either smoke cigarettes regularly or have quit smoking within the 2 months prior to the interview.

The questionnaire assessed participants' awareness of the 'Bubblewrap' campaign, their understanding of the main message of the advertisements, and whether they found them relevant and believable. After initial screening for eligibility and collection of selected demographic characteristics (age group, sex, place of usual residence), participants were asked whether they had tried to quit or cut down in the 2 months leading up to the interview and whether they had seen any advertising about the effects of smoking over this period. All participants were prompted with a screen shot of the television advertisement and a verbal description of the radio advertisement, and asked an open-ended question regarding the main message of the advertisements.

Participants who stated that they had seen and/or heard the advertisements were asked whether the advertising had prompted a change in their cigarette consumption (cutting down or quitting), and whether they had sought more information on quitting from their doctor or health worker, or discussed quitting with friends/family, as a result of seeing or hearing the advertising. This set of questions, and those dealing with the relevance and believability of the advertisements, required a simple 'yes/no' response.

The project methodology encompassed ethical and cultural considerations consistent with the Kulunga Research Network's
Aboriginal research principles framework and commitment to Aboriginal capacity building. Aboriginal people were consulted and genuinely engaged at all stages of the research. Study participants gave verbal consent to conduct the survey and no information was collected that could personally identify any participant.

\section{Analysis}

After the enumeration phase of the study, questionnaires were checked for internal consistencies and coded in preparation for data entry. After entry, further validation was performed on unit records and aggregate data, and relevant 'cleaning' performed. The unit record file was subsequently systematically analysed (univariate and cross tabulation analysis) using SPSS V.15 (SPSS, Chicago, Illinois, USA) and Stata V.10 (StataCorp, College Station, Texas, USA). $\chi^{2}$ tests were used to assess differences between study sites, sex and age groups, and McNemar $\chi^{2}$ tests were used to assess differences between advertising mediums.

\section{RESULTS}

\section{Sample}

In total, 429 people were approached in the course of undertaking the fieldwork for this study. Over half of these people did not have a questionnaire administered on the basis of refusal or ineligibility (non-smoker and/or non-Aboriginal). Interviews were conducted with 198 Aboriginal smokers; this group constituted $46 \%$ of all people approached. The survey response rate (the number of consenting in-scope people expressed as a proportion of all in-scope people) was at least $72 \%$. The sample had a relatively even age distribution, with roughly a quarter of the participants in each of the following age groups: 18-29 years; 30-39 years; $40-49$ years; and 50 years and above. There were slightly more female participants $(55 \%)$ than male participants (45\%).

\section{Awareness of advertising campaign}

Most of the participants (165, or $83.3 \%$ ) could recall seeing a television advertisement about the negative effects of smoking in the last 2 months and, when prompted, 178 (89.9\%) could recall seeing the television advertisement featured in this campaign At least $90 \%$ of the participants in each of the age groups under 50 years had seen the 'Bubblewrap' advertisement. Overall, participants aged 18-49 years were more likely to have seen the advertisement than participants aged 50 years and above $(93.4 \%$ compared with $71.9 \%, p<0.01)$. Females were more likely to have seen the advertisement than males (95.4\% compared with $83.2 \%$, $\mathrm{p}<0.01$ ), however there were no statistically significant differences in prompted awareness between the three study sites.

Less than a third $(58$, or $29.9 \%$ ) of the participants could remember hearing an antismoking radio advertisement in the last 2 months, and, when prompted, $67(34.0 \%)$ could recall the radio advertisement(s) featured in this campaign. These proportions highlight that there was significantly greater awareness of the television advertisement than the radio advertisement(s) $(\mathrm{p}<0.01)$. Participants in Broome were more likely to have heard the radio advertisement(s) than those in Perth $(50.0 \%$ compared with $28.0 \%, p=0.01)$ and Kalgoorlie (50.0\% compared with $25.5 \%, \mathrm{p}<0.01)$. There were no statistically significant differences in prompted awareness of the radio advertisement(s) between age groups or by sex.

\section{Response to advertising campaign}

The majority of participants who had seen the television advertisement and/or heard the radio advertisement(s) thought 
they were believable $(87.6 \%$ and $82.5 \%$ respectively, $p$ value for difference $=0.74$ ). Most participants also agreed that the television and radio advertisements were personally relevant to them $(83.7 \%$ and $77.4 \%$ respectively, $p$ value for difference $=0.53$ ).

Most participants (81.1\%) stated that the advertising made them think about cutting down the amount they smoked, while $68.1 \%$ of participants thought about quitting after seeing and/or hearing the advertisements.

The majority of participants (59.0\%) said that, as a result of the advertising, they had talked to family and friends about quitting, and $26.5 \%$ said that they got more information about quitting from their doctor or health worker as a result of the advertising.

Responses to the advertising campaign did not significantly differ across age groups or study sites, or by sex.

\section{Smoking behaviour}

A quarter $(25.1 \%)$ of the participants indicated that they had tried to quit in the 2 months prior to the study, while another $31.8 \%$ said that they had attempted to cut down. Overall, $30.3 \%$ of participants had successfully cut down their smoking to some degree in the last 2 months, while $1.5 \%$ had successfully quit smoking in the 2 months prior to the survey.

\section{DISCUSSION}

This study was one of the first large-scale evaluations of a mass media antismoking campaign conducted exclusively with Aboriginal people in Australia. The results suggest that this particular antismoking mass media campaign was effective in reaching Aboriginal smokers. The majority of the participants interviewed had seen the television advertisement and/or heard the radio advertisement(s), although there was significantly greater awareness of the former. This is consistent with past evaluations of the Cancer Council of Western Australia's antismoking campaigns, suggesting that television has a far greater reach than radio. The messages in this campaign appeared to be appropriate and acceptable for Aboriginal smokers, with the majority considering the advertising to be believable and relevant. Furthermore, the campaign appears to have encouraged Aboriginal smokers to think about cutting down and/or quitting.

The findings of this evaluation are very similar to those from a concurrent evaluation of the same campaign conducted with a sample of mainstream smokers. ${ }^{8}$ As with the Aboriginal smokers in this study, mainstream smokers had high prompted awareness of the television advertisement (89\%) and relatively low prompted awareness of the radio advertisement(s) (31\%). In addition, most mainstream smokers found the advertisements convincing (77\%) and relevant (76\%), and $48 \%$ seriously considered quitting as a result of the advertising. Other evaluations of the 'Bubblewrap' campaign among mainstream smokers in Australia have yielded similar awareness and impact results. ${ }^{9-11}$ Our findings are also consistent with those of studies in the Northern Territory ${ }^{6}$ and Victoria ${ }^{7}$ that investigated the impact of mass media antismoking campaigns on Aboriginal populations. Like this evaluation, these studies found that the majority of Aboriginal people could recall mainstream mass media antismoking campaigns. Taken together, all of these results suggest that Aboriginal and mainstream smokers respond in similar ways to mainstream antismoking media campaigns, and that mainstream campaigns can positively influence the thoughts and behaviours that Aboriginal smokers have, and exhibit, towards quitting smoking. Future large-scale evaluations of mainstream campaigns should be conducted with Aboriginal smokers to see if the findings of this study are replicated.

\section{What this paper adds}

Antismoking mass media campaigns have been shown to reduce smoking prevalence in the mainstream community, however there is little published research on their effect on Aboriginal Australian smokers.

- This evaluation of a mainstream mass media advertising campaign, conducted among Aboriginal smokers in Western Australia, found that the majority of participants had seen and/ or heard the advertisements and considered them to believable and relevant. The findings of this study suggest that mainstream antismoking mass media campaigns can positively influence the thoughts and behaviours that Aboriginal smokers have, and exhibit, towards quitting smoking.

This study had several limitations. The evaluation was restricted to the post campaign period, so we are unable to assess if the campaign directly led to an actual increase in quitting among Aboriginal smokers, a change in quitting intentions or a better understanding of the negative health effects of smoking. In addition, limitations in questionnaire wording meant that we could not get a measure of unprompted awareness for either form of advertising, nor could we individually assess the effectiveness of the original and new radio advertisements on the behaviours of Aboriginal smokers. This restricted what could be inferred from this study about the benefits of targeted versus mainstream antismoking advertising.

Previous research has consistently shown that stress ${ }^{12-14}$ and the normalisation of tobacco smoking ${ }^{12} 1516$ are major barriers to smoking cessation among Aboriginal smokers. Little is known, however, about what motivates Aboriginal smokers to quit, or to not smoke at all (ie, to be classified a never smoker). ${ }^{17}$ A better understanding of these motivations, as well as factors that can diminish campaign impact among Indigenous populations, may lead to more effective advertising campaigns. Although the results of this evaluation, as well as other studies, suggest that mainstream antismoking mass media campaigns are effective at reaching Aboriginal smokers, it is important that those developing antismoking campaigns investigate better ways to incorporate Aboriginal themes in their messages. Additionally, these results highlight the need for sufficient funding of future antismoking campaigns to ensure that advertising messages reach the large Aboriginal populations in regional and remote Australia.

Acknowledgements Many thanks to Marita Smith, Peta Gooda, Stephanie Hall, Colleen Hayward, Jackie Goldfinch and Tracey-Lee Edwards for their contributions to this study. CCJS is supported by a Sidney Myer Health Scholarship.

Contributors TB and CCJS were responsible for the data analysis and interpretation and are the primary authors of the manuscript; all authors contributed to the study design and review of the manuscript; TB, CCJS, GP and HM were involved in the data collection phase of the study.

Funding Kulunga Research Network was commissioned by the Cancer Council Western Australia to conduct this evaluation.

\section{Competing interests None.}

Ethics approval The research was of negligible risk and no information was collected that could personally identify any participant. The project methodology encompassed ethical and cultural considerations consistent with the Kulunga Research Network's Aboriginal research principles framework and commitment to Aboriginal capacity building. Aboriginal people were consulted and genuinely engaged at all stages of the research.

Provenance and peer review Not commissioned; externally peer reviewed. 


\section{REFERENCES}

1. Australian Bureau of Statistics. Tobacco smoking in Australia: a snapshot, 2004-05. Canberra, Australia: Australian Bureau of Statistics, 2006. http://www.abs. gov.au/ausstats/abs@.nst/mf/4722.0.55.004 (accessed 10 Nov 2008).

2. Australian Bureau of Statistics, Australian Institute of Health and Welfare. The health and welfare of Australia's Aboriginal and Torres Strait Islander Peoples 2008. Canberra, Australia: Australian Bureau of Statistics and Australian Institute of Health and Welfare, 2008. http://www.aihw.gov.au/publications/index.cfm/title/ 10583 (accessed 10 Nov 2008).

3. Vos T, Barker B, Stanley L, et al. The burden of disease and injury in Aboriginal and Torres Strait Islander peoples 2003. Brisbane, Australia: School of Population Health, The University of Queensland, 2007. http://www.uq.edu.au/bodce/index.html? page $=68411$ (accessed 12 Nov 2008).

4. Pierce JP, Macaskill P, Hill D. Long-term effectiveness of mass media led antismoking campaigns in Australia. Am J Public Health 1990;80:565-9.

5. Wakefield MA, Durkin S, Spittal MJ, et al. Impact of tobacco control policies and mass media campaigns on monthly adult smoking prevalence. Am J Public Health 2008;98:1443-50.

6. Ivers $\mathbf{R}$, Castro A, Parfitt D, et al. Television and delivery of health promotion programs to remote Aboriginal communities. Health Promot J Austr 2005;16:155-8.

7. Murphy M, Mee V. The impact of the national Tobacco Campaign on Indigenous communities: a study in Victoria. In: Hassard K, ed. Evaluation report volume one. Canberra, Australia: Commonwealth Department of Health and Aged Care, 1999. http://www.quitnow.info.au/internet/quitnow/publishing.nsf/content/evaluationreports (accessed on 12 Nov 2008).

8. TNS Social Research. 'Bubblewrap' campaign evaluation report 2008. West Perth, Australia: TNS Social Research, 2008
9. Durkin S, Wakefield M. Responses to the 'Bubblewrap Emphysema' campaign CBRC Research Paper Series No. 19. Melbourne, Australia: Centre for Behavioural Research in Cancer, The Cancer Council Victoria, 2006. http://www.cancervic.org.au/browse. asp?ContentID=abstract response to bubblewrap (accessed on 18 Aug 2009).

10. Jalleh G, Donovan R. Evaluation of the 'Make Smoking History' campaign: wave 10 Perth, Australia: Centre for Behavioural Research in Cancer Control, Division of Health Sciences, Curtin University of Technology, 2005.

11. Durkin S, Wakefield M. Maximizing the impact of emotive antitobacco advertising: effects of interpersonal discussion and program placement. Soc Mar 0 2006;12:3-14

12. Wood L, France K, Hunt K, et al. Indigenous women and smoking during pregnancy: knowledge, cultural contexts and barriers to cessation. Soc Sci Med 2008;66:2378-89.

13. Mark A, McLeod I, Booker J, et al. Aboriginal health worker smoking: a barrier to lower community smoking rates? Aborig Is/ Health Work J 2005;29:22-6.

14. DiGiacomo M, Davidson PM, Davison J, et al. Stressful life events, resources, and access: key considerations in quitting smoking at an Aboriginal Medical Service. Aust N Z J Public Health 2007;31:174-6.

15. Briggs V, Lindorff K, Ivers R. Aboriginal and Torres Strait Islander Australians and tobacco. Tob Control 2003;12(Suppl II):ii5-8.

16. Johnston V, Thomas D. Smoking behaviours in a remote Australian Indigenous community: the influence of family and other factors. Soc Sci Med 2008;67:1708-16.

17. Centre for Excellence in Indigenous Tobacco Control (CEITC). Indigenous tobacco control in Australia: everybody's business, national Indigenous tobacco control research roundtable report, Brisbane, Australia, 23 May 2008. Melbourne, Australia: CEITC, The University of Melbourne, 2008. http://www.ceitc.org.au/ ceitc_publications (accessed on 3 May 2009). 


\section{TC}

\section{Awareness and impact of the 'Bubblewrap' advertising campaign among Aboriginal smokers in Western Australia}

Terry Boyle, Carrington C J Shepherd, Glenn Pearson, et al.

Tob Control 2010 19: 83-86 originally published online December 3, 2009

doi: 10.1136/tc.2009.031856

Updated information and services can be found at:

http://tobaccocontrol.bmj.com/content/19/1/83.full.html

\section{These include:}

References This article cites 9 articles, 3 of which can be accessed free at: http://tobaccocontrol.bmj.com/content/19/1/83.full.html\#ref-list-1

Email alerting

Receive free email alerts when new articles cite this article. Sign up in service the box at the top right corner of the online article.

Notes

To request permissions go to:

http://group.bmj.com/group/rights-licensing/permissions

To order reprints go to:

http://journals.bmj.com/cgi/reprintform

To subscribe to BMJ go to:

http://group.bmj.com/subscribe/ 